Case Report

\title{
Maxillary Sinus Lift Using Autologous Periosteal Micrografts: A New Regenerative Approach and a Case Report of a 3-Year Follow-Up
}

\author{
Saturnino Marco Lupi $\left(\mathbb{D},{ }^{1}\right.$ Arianna Rodriguez y Baena, ${ }^{1}$ Claudia Todaro, ${ }^{1}$ \\ Gabriele Ceccarelli (iD), ${ }^{2}$ and Ruggero Rodriguez y Baena ${ }^{1}{ }^{1}$ \\ ${ }^{1}$ Department of Clinical Surgical, Diagnostic and Pediatric Sciences, University of Pavia, Pavia, Italy \\ ${ }^{2}$ Department of Public Health, Experimental Medicine and Forensic, Human Anatomy Unit, University of Pavia, Pavia, Italy \\ Correspondence should be addressed to Ruggero Rodriguez y Baena; ruggero.rodriguez@unipv.it
}

Received 24 January 2018; Accepted 14 June 2018; Published 24 July 2018

Academic Editor: Gerardo Gómez-Moreno

Copyright (c) 2018 Saturnino Marco Lupi et al. This is an open access article distributed under the Creative Commons Attribution License, which permits unrestricted use, distribution, and reproduction in any medium, provided the original work is properly cited.

\begin{abstract}
This case report discusses about an innovative bone regeneration method that involves the use of autologous periosteal micrografts, which were used for a maxillary sinus floor lift in a 52-year-old female patient. This method allows for harvesting of a graft that is to be seeded on a PLGA scaffold and involves collection of a very little amount of palatal periosteal tissue in the same surgical site after elevation of a flap and disaggregation of it by using a Rigenera ${ }^{\circledR}$ filter. Histological samples collected at the time of implant installation demonstrate a good degree of bone regeneration. The clinical and radiographic outcomes at the 3-year follow-up visit showed an adequate stability of hard and soft tissues around the implants. This report demonstrates the possibility to obtain a sufficient quality and quantity of bone with a progenitor cell-based micrograft and in turn make the site appropriate for an implant-supported rehabilitation procedure, with stable results over a period of two years.
\end{abstract}

\section{Introduction}

Tooth loss causes alveolar bone resorption that often limits implant placement. In the superior maxilla, this process is associated with the pneumatization of the sinus [1-3].

Since the 60 s, numerous surgical techniques have been proposed for the regeneration of maxillary bone defects. When the residual bone height is inadequate for implant placement, in case of favorable prosthetical spaces, a sinus lift is considered a safe procedure with predictable results [4-10]. Implant placement is contraindicated if the residual bone height is less than $5 \mathrm{~mm}$ [11].

Current treatment options for bone defects include autologous, homologous, xenologous, and allogenous grafts; artificial bone substitutes can be synthetic or bioceramic cements or a blend of two or more materials [12]. Although several studies have been conducted to identify the best graft material for sinus floor augmentation, a final consensus has not been reached [4]. Autologous bone grafts represent the gold standard graft material because these exhibit osteoinductive, osteoconductive, and osteogenic properties. However, the use of this material remains limited owing to rapid resorption, collection of inadequate amounts of tissue if harvested intraorally, donor site morbidity, and high biologic cost [13]. Alternatively, the alloplastic bone substitutes and the xenologous bone show high availability, biocompatibility, and good mechanical support and also have adequate porosity that allows for penetration of blood capillaries, which is essential for the supply of oxygen, nutrients, and growth factors [14-19]. However, these bone substitutes are limited by the fact that they do not carry osteogenic cells and osteoinductive molecules, which are important for tissue regeneration [20-23].

In the last twenty years, researchers have shown renewed interest in developing new regeneration methods. Researchers are particularly focusing on mesenchymal stem cells because they represent a self-renewable reservoir of cells that can proliferate and differentiate at the same time. 


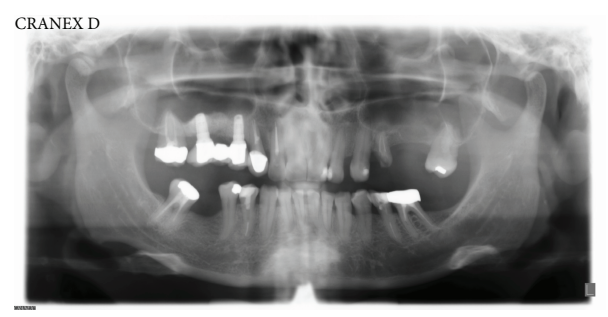

FIgURE 1: Preoperative panoramic radiograph of the patient.

Thus, if correctly transplanted, mesenchymal stem cells are able to regenerate a particular tissue [24-28].

Unfortunately, stem cell therapies require both highly developed technologies and methods, which are not yet allowed to be used in many countries (e.g., laboratory handling of stem cells to produce tissues). Moreover, a few researchers have reported that stem cell therapies could increase the risk for tumor growth [29-34].

Recently, a class I medical device (Rigeneracons ${ }^{\circledR}$, Human Brain Wave S.R.L., Torino, Italy) has been introduced in clinical practice in order to disaggregate a portion of tissue and obtain $50 \mu \mathrm{m}$ viable micrografts full of progenitor cells, while maintaining their regenerative and differentiation potentials. These micrografts can be obtained from a sample of autologous connective tissue few millimeters in length, which is harvested directly during the surgery, even from the same surgical site, and can be immediately used without any handling or cell culture [35].

The aim of this report is to present a clinical case in which autologous micrografts with a high percentage of progenitor cells were seeded on a PLGA hydroxyapatite- (HA-) enriched scaffold for a sinus floor lift augmentation procedure and to present the histological features shown by the sample collected at the implant site and the radiographic aspect obtained three years after the lift procedure.

\section{Case Report}

2.1. Materials and Methods. The procedure discussed in this case report was performed at the Department of Clinical Surgical, Diagnostic and Paediatric Sciences, University of Pavia, Italy, and the procedure was approved by the University Ethics Committee (recorded March 2014).

A 52-year-old woman, with a good health status (ASA score: 0), was enrolled for the study; written informed consent was obtained from the patient to have the case details and any accompanying images anonymously published. She was indicated for a prosthetic implant rehabilitation procedure in the second quadrant after a maxillary sinus lift procedure for atrophy of the maxillary bone at the bicuspid and molar level ( $1 \mathrm{~mm}$ residual bone crest height) in order to collect enough bone to install two endosseous implants (Figures 1 and 2).

The patient was prepared for the surgery with scaling and root planning two weeks prior to the sinus floor lift. The surgery was performed under antibiotic prophylaxis: amoxicillin plus clavulanic acid (Augmentin, GlaxoSmithKline S.p.A., Verona, Italy), 2 gr 1 hour before the surgery. For the

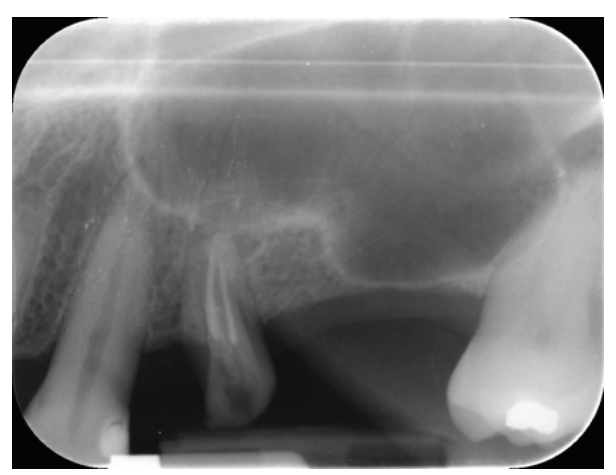

FIGURE 2: Intraoral radiograph (Rinn ${ }^{\circledR}$ collimator) of the surgery site.

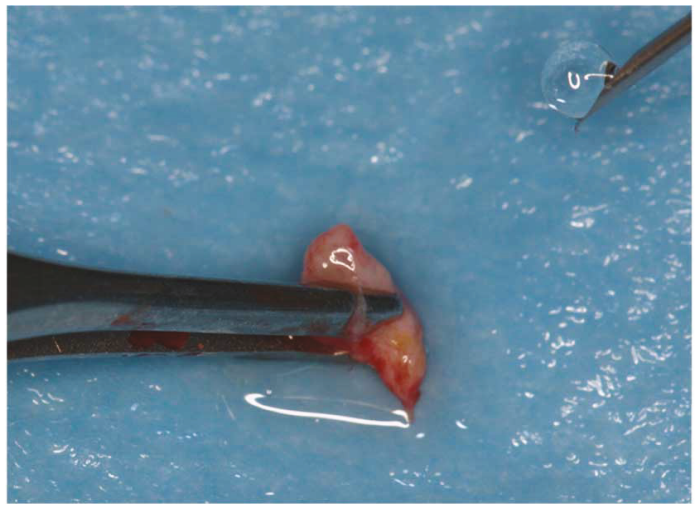

FIgURE 3: Connective tissue collected directly from the surgery site.

local anesthesia, articain 4\% with 1/200000 epinephrine was used.

A full-thickness flap was lifted via mesial and distal relief incisions. From the palatal flap, a $3 \mathrm{~mm}$ periosteal sample was harvested and then washed with a sterile saline solution. Then, it was inserted in the Rigeneracons filter with $1 \mathrm{ml}$ of sterile saline for the disaggregation process (Figures 3 and 4).

Tissue graft disaggregation was performed for 2 minutes at $70 \mathrm{rpm}$ and $15 \mathrm{Ncm}$ torque, and the cell suspension was withdrawn with a sterile syringe and added to the PLGAHA scaffold (Alos ${ }^{\circledR}$, Allmed srl, Lissone, MB, Italy) in order to be grafted into the new subantral cavity (Figure 5). In the meantime, the receiving site was prepared according to the standard protocol used for lateral sinus floor augmentation (Figure 6) [11, 14]. The wall osteotomy was performed with Piezosurgery $^{\circledR}$ (Mectron S.p.A., Carasco, GE, Italy) using an OT5 insert. A resorbable membrane (Bio-Gide ${ }^{\circledR}$, Geistlich Pharma AG, Wolhusen, Switzerland) was positioned in the newly formed subantral cavity to preserve the sinus membrane, and the space was then filled with the blend of PLGA and micrograft (Figures 6 and 7). The bone window was covered with collagen sponges (Gingistat ${ }^{\circledR}$, Pierre Rolland Pharmaceutical, Merignac, Aquitaine, France) soaked in the cell suspension and a resorbable membrane (Bio-Gide, Geistlich Pharma, Wolhusen, Switzerland) (Figure 8). The flap was sutured with a 4-0 PTFE suture (Omnia S.p.A, Fidenza, PR, Italy). 


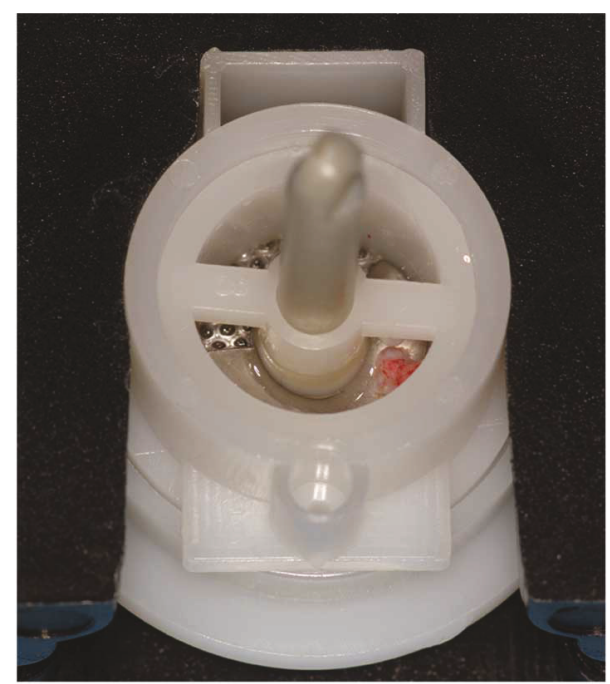

Figure 4: Tissue graft disaggregation with the Rigeneracons device, according to the manufacturer's instructions: $1 \mathrm{ml}$ of sterile saline solution, performed for 120 seconds with implant contra-angle at $15 \mathrm{NCm}$ and $70 \mathrm{rpm}$.

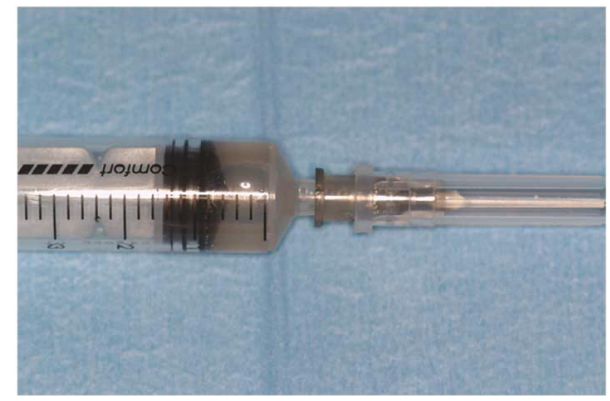

FIGURE 5: The syringe with progenitor cell-enriched suspension obtained via the periosteum disaggregation process.

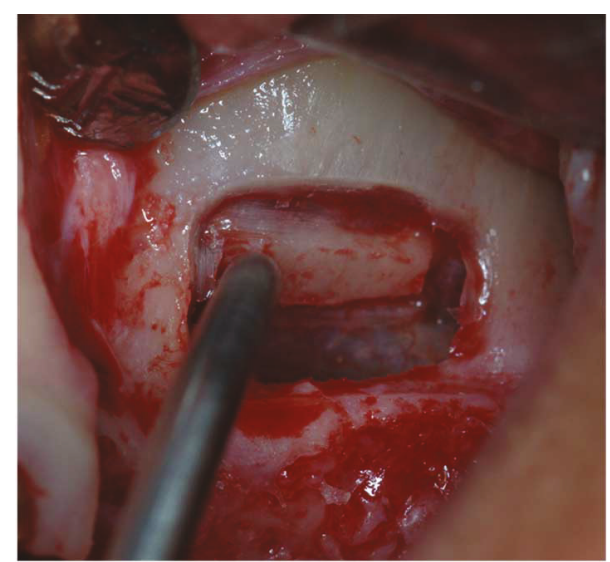

FIgURE 6: The window elevation.

During the postoperative period, the patient received antibiotic therapy ( 1 gr every 12 hours of amoxicillin + clavulanic acid for 7 days) and performed oral rinses with chlorhexidine $0.2 \%$ (Curasept ${ }^{\circledR}$, Curaden Healthcare S.p.A.,

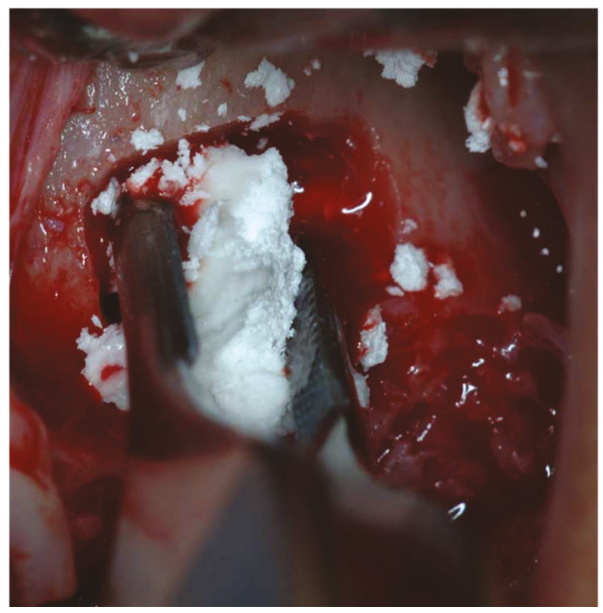

Figure 7: The biocomplex graft placement in the maxillary sinus, under the Schneider membrane.

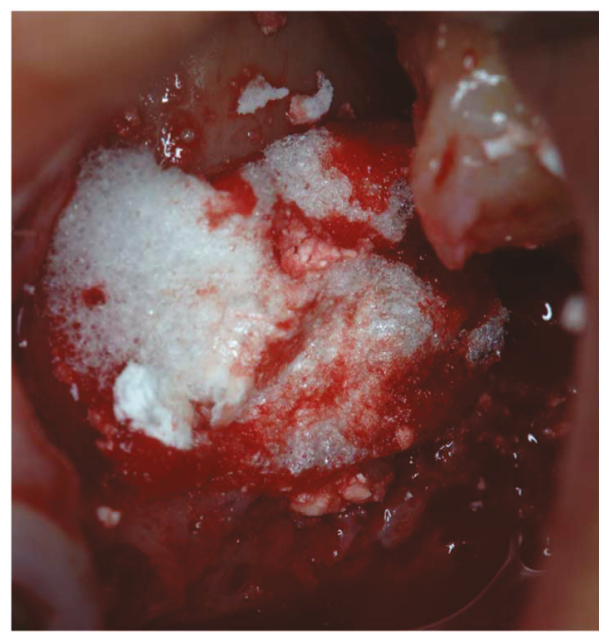

Figure 8: Covering the osteotomy access with collagen and resorbable membrane.

Saronno, VA, Italy), 3 times/day for 30 days, and she was administered nonsteroidal anti-inflammatory drugs (NSAIDs) if needed.

The healing was uneventful and the sutures were removed after 2 weeks.

At 4 months after the surgery, following a cone-beam CT examination demonstrating a good level of bone regeneration, a mucoperiosteal flap was elevated and two bone tissue carrots $3 \mathrm{~mm}$ in diameter were harvested from the implant sites using a trephine bur. Two $3.8 \times 9 \mathrm{~mm}$ implants were installed (Camlog ${ }^{\circledR}$ Promote $^{\circledR}$ Plus, Camlog Biotechnologies AG, Basel, Switzerland) according to the standard protocol [36]. The insertion torque was $25 \mathrm{~N} / \mathrm{cm}$. The mucosal flap covered the fixtures during the healing phase, and the sutures were removed after 10 days. No adverse events occurred (Figure 9).

The collected tissues were fixed in a $10 \%$ formalin solution and then prepared for microscopic observation in order to determine the ossification grade (Figure 10). Paraffinembedded tissue sections were cut into $5 \mu \mathrm{m}$-thick slices, 


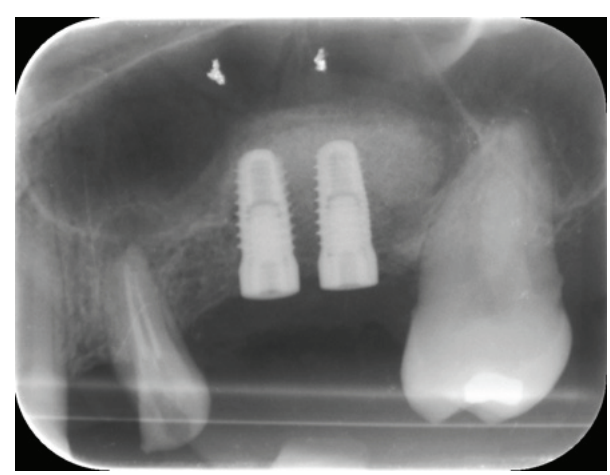

FIGURE 9: Radiograph taken postimplantation.

following which the paraffin slices were immersed in xylene and then in decreasing grades of ethanol (100\% to $75 \%)$ and deionized water for deparaffinizing and rehydrating the sections. Subsequently, the slide sections were stained with hematoxylin for 1-2 minutes and rinsed in cold water to remove excess stain. The sections were then stained with eosin for 4-5 minutes and rinsed under running tap water. The tissue sections were then immersed in increasing grades of ethanol (from $50 \%$ to $100 \%$ ), and finally after an immersion in xylene, they were coverslipped with a mounting medium. Histological analyses demonstrated that the combination of micrografts with the PLGA scaffold allowed the ossification process. In fact, at $40 \mathrm{x}$ magnification (Figure 10(b)), lamellar bone formation was observed, as seen by the presence of a typical Haversian system with the deposition of a calcified matrix.

8 weeks after the implant installation, the following standard prosthetic procedures were performed: implant impression, abutment and structure proof, and cemented prosthesis delivery.

After three years, during the follow-up visit [37], radiographs were taken, which demonstrated an excellent stability of the graft and of the regenerated bone and the success of the rehabilitation (Figure 11).

\section{Discussion}

Usually, a bone graft is the first therapeutic option in cases where the amount of bone is inadequate for implant installation. Autologous bone is considered the gold standard in sinus augmentation procedures but exposes to donor site morbidity. With the Rigenera protocol, the amount of tissue harvested is very little and the donor site is the surgical site itself, thus minimizing the risk of morbidity. In the presented clinical case, healing was uneventful and no sign of tissue harvesting resituated in the palatal flap. The authors did not observe any differences in postoperative soft tissue healing and patient morbidity with respect to the standard procedure due to soft tissue harvesting from the palatal flap. Synthetic materials exhibit a good capability to regenerate an adequate amount of bone, but they do not exhibit the osteoinductive and osteogenic properties needed for bone regeneration. Furthermore, some of these materials show a lack of resorbability even after years from the time of production. This is the reason why the field of bone tissue engineering has focused on techniques such as the use of mesenchymal stem cells [38]. Although many reports suggest that stem cell-based tissue engineering is beneficial, general critiques of cell therapy approaches have included the lack of characterization of the cellular component of the graft [27]. Previous evaluation of micrografts produced by the Rigenera protocol indicated that these cells are positive to mesenchymal cell line markers and negative to hematopoietic and macrophage markers. In fact, cell characterization performed by FACS was positive for several mesenchymal cell markers, including CD90, CD105, and CD73, and negative for CD45 and CD14. Moreover, the Rigenera protocol demonstrated to be able to produce in a few minutes (about $2 \mathrm{~min}$ ) a cell suspension containing millions of viable cells with a cutoff of $50 \mu \mathrm{m}$, opportunely selected by filtration [35]. The behavior of these cells is not clearly known yet, and it could present some risks. However, many studies regarding this topic are being conducted and some researchers have also proposed to use patients' mesenchymal cell micrograft directly, so that the patient is the donor and the receiver at the same time.

A licit criticism related to the use of MSC in a therapeutic procedure is that the graft cell population is composed of nonclonal stromal cells containing stem cells, progenitor cells, and differentiated mesodermal cells, including fibroblasts, and that the advantages connected to their use are more related to their important role in modulating inflammation compared to any stem cell activity [39].

It was demonstrated that micrografts obtained by the Rigenera protocol are able to maintain the osteogenic and regenerative properties because of the content of the progenitor cells [35, 38]. In fact, histological analysis also suggested that the Rigenera protocol facilitates ossification process in the surgical site. In Figure 10, hematoxylin/eosin staining showed the formation of a new bone at 4 months after the maxillary sinus lift procedure, suggesting that the combination of the appropriate biomaterials and the micrografts accelerated the bone-healing process. In particular, the histological analysis showed the presence of bone lamellae, which are concentric rings of bone, surrounding a central channel, or the Haversian canal, containing nerves, blood vessels, and lymph (Figures 10(a) and 10(b)). These lamellae are produced by osteoblasts that secrete extracellular bone matrix with collagen fibers and inorganic phosphate.

The sinus lift surgery performed in this case was associated with a resorbable scaffold HA enriched with progenitor cell micrograft, which was harvested from the palatal periosteum. In particular, the small tissue sample was derived directly from the surgery flap, so the biologic cost was very low.

The scaffold is important to provide the stability and mechanical resistance required to maintain the viability of the cells. Different types of osteoconductive materials could be used as scaffolds. In this case, we chose the PLGA HAenriched scaffold, which was completely resorbable, as PLGA without HA, but also offered more stability to the graft because of the presence of hydroxyapatite. The micrografts, 


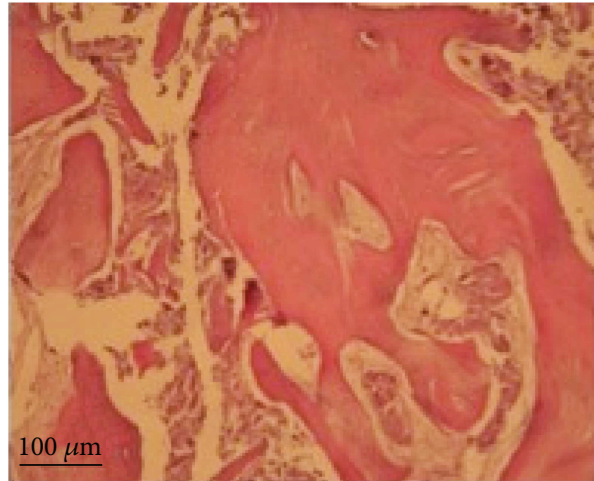

(a)

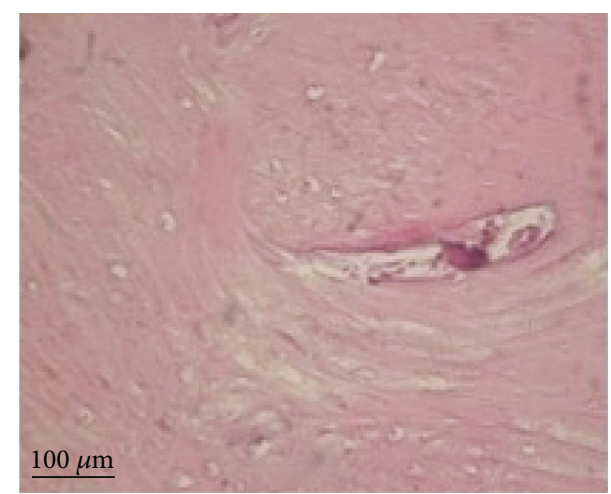

(b)

Figure 10: Hematoxylin/eosin staining of samples at 4 months (a,b) after grafting with the Rigenera system. (a) 10x magnification, (b) 40x magnification.

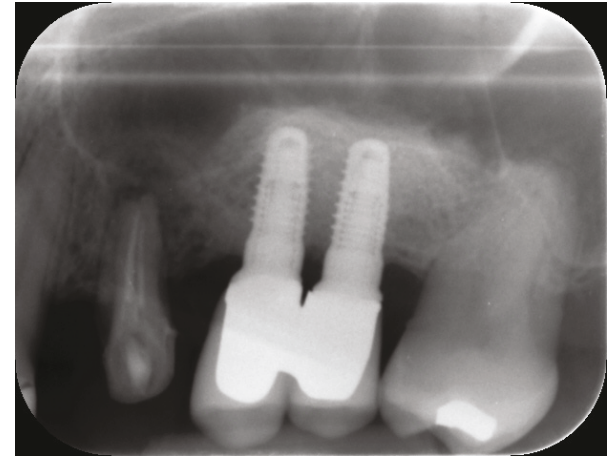

FIgURE 11: Intraoral radiograph taken after 3 years.

compared with the other bone grafts, are effective in the regeneration of bone required for implant surgery and are capable of supporting long-term prosthetical load [40, 41].

\section{Conclusion}

This case illustrates that the use of autologous micrografts, which are rich in progenitor cells, in the sinus floor lift procedure is effective in regenerating an adequate amount of bone tissue, with both excellent implant stability and minimum biological sacrifice.

\section{Abbreviations}

PLGA: Poly lactic-co-glycolic acid

NSAID: Nonsteroidal anti-inflammatory drugs

ASA: The American Society of Anesthesiologists.

\section{Conflicts of Interest}

The authors declare that they have no conflicts of interest.

\section{References}

[1] M. Peleg, Z. Mazor, and A. K. Garg, "Augmentation grafting of the maxillary sinus and simultaneous implant placement in patients with 3 to $5 \mathrm{~mm}$ of residual alveolar bone height,"
The International Journal of Oral \& Maxillofacial Implants, vol. 14, no. 4, pp. 549-556, 1999.

[2] G. Tawil and M. Mawla, "Sinus floor elevation using a bovine bone mineral (Bio-Oss) with or without the concomitant use of a bilayered collagen barrier (Bio-Gide): a clinical report of immediate and delayed implant placement," The International Journal of Oral \& Maxillofacial Implants, vol. 16, no. 5, pp. 713-721, 2001.

[3] M. J. Kim, U. W. Jung, C. S. Kim et al., "Maxillary sinus septa: prevalence, height, location, and morphology. A reformatted computed tomography scan analysis," Journal of Periodontology, vol. 77, no. 5, pp. 903-908, 2006.

[4] O. T. Jensen, L. B. Shulman, M. S. Block, and V. J. Iacono, "Report of the Sinus Consensus Conference of 1996," The International Journal of Oral \& Maxillofacial Implants, vol. 13, pp. 11-45, 1998.

[5] S. S. Wallace and S. J. Froum, "Effect of maxillary sinus augmentation on the survival of endosseous dental implants. A systematic review," Annals of Periodontology, vol. 8, no. 1, pp. 328-343, 2003.

[6] M. Del Fabbro, T. Testori, L. Francetti, and R. Weinstein, "Systematic review of survival rates for implants placed in the grafted maxillary sinus," The International Journal of Periodontics \& Restorative Dentistry, vol. 24, no. 6, pp. 565-577, 2004.

[7] M. Piattelli, G. A. Favero, A. Scarano, G. Orsini, and A. Piattelli, "Bone reactions to anorganic bovine bone (Bio-Oss) used in sinus augmentation procedures: a histologic long-term report of 20 cases in humans," The International Journal of Oral \& Maxillofacial Implants, vol. 14, no. 6, pp. 835-840, 1999.

[8] P. Valentini, D. Abensur, B. Wenz, M. Peetz, and R. Schenk, "Sinus grafting with porous bone mineral (Bio-Oss) for implant placement: a 5-year study on 15 patients," The International Journal of Periodontics \& Restorative Dentistry, vol. 20, no. 3, pp. 245-253, 2000.

[9] M. Yildirim, H. Spiekermann, S. Biesterfeld, and D. Edelhoff, "Maxillary sinus augmentation using xenogenic bone substitute material Bio-Oss ${ }^{\circledR}$ in combination with venous blood. A histologic and histomorphometric study in humans," Clinical Oral Implants Research, vol. 11, no. 3, pp. 217-229, 2000.

[10] M. Hallman, A. Cederlund, S. Lindskog, S. Lundgren, and L. Sennerby, "A clinical histologic study of bovine hydroxyapatite in combination with autogenous bone and fibrin glue for 
maxillary sinus floor augmentation. Results after 6 to 8 months of healing," Clinical Oral Implants Research, vol. 12, no. 2, pp. 135-143, 2001.

[11] M. Chiapasco, M. Zaniboni, and L. Rimondini, "Dental implants placed in grafted maxillary sinuses: a retrospective analysis of clinical outcome according to the initial clinical situation and a proposal of defect classification," Clinical Oral Implants Research, vol. 19, no. 4, pp. 416-428, 2008.

[12] G. Ceccarelli, R. Presta, L. Benedetti, M. G. Cusella de Angelis, S. M. Lupi, and R. Rodriguez y Baena, "Emerging perspectives in scaffold for tissue engineering in oral surgery," Stem Cells International, vol. 2017, Article ID 4585401, 11 pages, 2017.

[13] C. J. Damien and J. R. Parsons, "Bone graft and bone graft substitutes: a review of current technology and applications," Journal of Applied Biomaterials, vol. 2, no. 3, pp. 187-208, 1991.

[14] S. Scaglione, P. Giannoni, P. Bianchini et al., "Order versus disorder: in vivo bone formation within osteoconductive scaffolds," Scientific Reports, vol. 2, no. 1, p. 274, 2012.

[15] D. Bollati, M. Morra, C. Cassinelli, S. M. Lupi, and R. Rodriguez y Baena, "In vitro cytokine expression and in vivo healing and inflammatory response to a collagencoated synthetic bone filler," BioMed Research International, vol. 2016, Article ID 6427681, 10 pages, 2016.

[16] R. Rodriguez y Baena, S. M. Lupi, R. Pastorino, C. Maiorana, A. Lucchese, and S. Rizzo, "Radiographic evaluation of regenerated bone following poly(lactic-co-glycolic) acid/hydroxyapatite and deproteinized bovine bone graft in sinus lifting," The Journal of Craniofacial Surgery, vol. 24, no. 3, pp. 845-848, 2013.

[17] R. R. Betz, "Limitations of autograft and allograft: new synthetic solutions," Orthopedics, vol. 25, no. 5, pp. s561-s570, 2002.

[18] C. G. Finkemeier, "Bone-grafting and bone-graft substitutes," The Journal of Bone \& Joint Surgery, vol. 84, no. 3, pp. 454464, 2002.

[19] R. Rodriguez y Baena, R. Pastorino, E. Gherlone, L. Perillo, S. Saturnino, and A. Lucchese, "Histomorphometric evaluation of two different bone substitutes in sinus augmentation procedures: a randomized controlled trial in humans," The International Journal of Oral \& Maxillofacial Implants, vol. 32, no. 1, pp. 188-194, 2017.

[20] Z. Zhang, "Bone regeneration by stem cell and tissue engineering in oral and maxillofacial region," Frontiers in Medicine, vol. 5, no. 4, pp. 401-413, 2011.

[21] S. P. Bruder and B. S. Fox, "Tissue engineering of bone. Cell based strategies," Clinical Orthopaedics and Related Research, vol. 367, pp. S68-S83, 1999.

[22] G. J. Meijer, J. D. de Bruijn, R. Koole, and C. A. van Blitterswijk, "Cell-based bone tissue engineering," PLoS Medicine, vol. 4, no. 2, article e9, 2007.

[23] R. Schmelzeisen, R. Schimming, and M. Sittinger, "Making bone: implant insertion into tissue-engineered bone for maxillary sinus floor augmentation-a preliminary report," Journal of Cranio-Maxillo-Facial Surgery, vol. 31, no. 1, pp. 34-39, 2003.

[24] D. Baksh, L. Song, and R. S. Tuan, "Adult mesenchymal stem cells: characterization, differentiation, and application in cell and gene therapy," Journal of Cellular and Molecular Medicine, vol. 8, no. 3, pp. 301-316, 2004.
[25] P. Bianco and P. G. Robey, "Stem cells in tissue engineering," Nature, vol. 414, no. 6859, pp. 118-121, 2001.

[26] M. F. Pittenger, A. M. Mackay, S. C. Beck et al., "Multilineage potential of adult human mesenchymal stem cells," Science, vol. 284, no. 5411, pp. 143-147, 1999.

[27] H. Egusa, W. Sonoyama, M. Nishimura, I. Atsuta, and K. Akiyama, "Stem cells in dentistry - part II: clinical applications," Journal of Prosthodontic Research, vol. 56, no. 4, pp. 229-248, 2012.

[28] G. Ceccarelli, R. Presta, S. Lupi et al., "Evaluation of poly(lacticco-glycolic) acid alone or in combination with hydroxyapatite on human-periosteal cells bone differentiation and in sinus lift treatment," Molecules, vol. 22, no. 12, 2017.

[29] M. Battiwalla and P. Hematti, "Mesenchymal stem cells in hematopoietic stem cell transplantation," Cytotherapy, vol. 11, no. 5, pp. 503-515, 2009.

[30] G. Lucchini, M. Introna, E. Dander et al., "Platelet-lysateexpanded mesenchymal stromal cells as a salvage therapy for severe resistant graft-versus-host disease in a pediatric population," Biology of Blood and Marrow Transplantation, vol. 16, no. 9, pp. 1293-1301, 2010.

[31] A. Giordano, U. Galderisi, and I. R. Marino, "From the laboratory bench to the patient's bedside: an update on clinical trials with mesenchymal stem cells," Journal of Cellular Physiology, vol. 211, no. 1, pp. 27-35, 2007.

[32] R. Pal, N. K. Venkataramana, A. Bansal et al., "Ex vivoexpanded autologous bone marrow-derived mesenchymal stromal cells in human spinal cord injury/paraplegia: a pilot clinical study," Cytotherapy, vol. 11, no. 7, pp. 897-911, 2009.

[33] L. Sun, K. Akiyama, H. Zhang et al., "Mesenchymal stem cell transplantation reverses multiorgan dysfunction in systemic lupus erythematosus mice and humans," Stem Cells, vol. 27, no. 6, pp. 1421-1432, 2009.

[34] S. G. Hong, T. Winkler, C. Wu et al., "Path to the clinic: assessment of iPSC-based cell therapies in vivo in a nonhuman primate model," Cell Reports, vol. 7, no. 4, pp. 1298-1309, 2014.

[35] L. Trovato, M. Monti, C. del Fante et al., "A new medical device Rigeneracons allows to obtain viable micro-grafts from mechanical disaggregation of human tissues," Journal of Cellular Physiology, vol. 230, no. 10, pp. 2299-2303, 2015.

[36] S. Rizzo, P. Zampetti, R. Rodriguez Y Baena, D. Svanosio, and S. M. Lupi, "Retrospective analysis of 521 endosseous implants placed under antibiotic prophylaxis and review of literature," Minerva Stomatologica, vol. 59, no. 3, pp. 75-88, 2010.

[37] S. M. Lupi, M. Granati, A. Butera, V. Collesano, and R. Rodriguez Y Baena, "Air-abrasive debridement with glycine powder versus manual debridement and chlorhexidine administration for the maintenance of peri-implant health status: a six-month randomized clinical trial," International Journal of Dental Hygiene, vol. 15, no. 4, pp. 287-294, 2017.

[38] R. d'Aquino, L. Trovato, A. Graziano et al., "Periosteumderived micro-grafts for tissue regeneration of human maxillary bone," Journal of Translational Science, vol. 2, no. 2, pp. 125-129, 2016.

[39] U. Galderisi and A. Giordano, "The gap between the physiological and therapeutic roles of mesenchymal stem cells," Medicinal Research Reviews, vol. 34, no. 5, pp. 1100-1126, 2014. 
[40] D. Zaffe, R. Rodriguez y Baena, S. Rizzo et al., "Behavior of the bone-titanium interface after push-in testing: a morphological study," Journal of Biomedical Materials Research, vol. 64A, no. 2, pp. 365-371, 2003.

[41] R. Rodriguez y Baena, D. Zaffe, U. E. Pazzaglia, and S. Rizzo, "Morphology of peri-implant regenerated bone, in sheep's tibia, by means of guided tissue regeneration," Minerva Stomatologica, vol. 47, no. 12, pp. 673-687, 1998. 


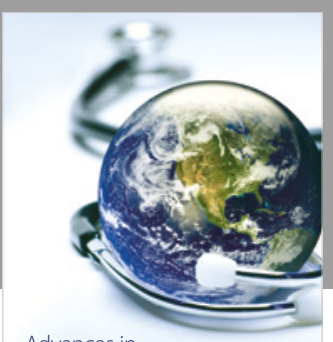

Advances in
Public Health

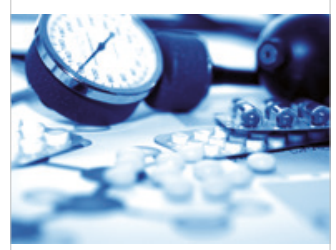

Case Reports in

Medicine

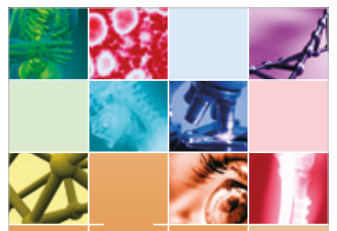

niernational Journal of

Biomaterials
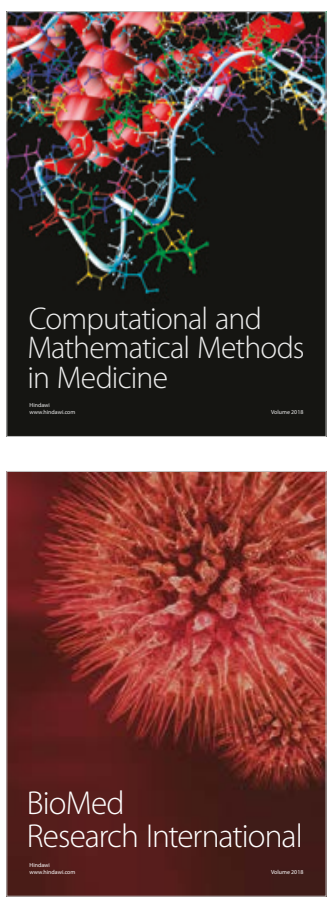

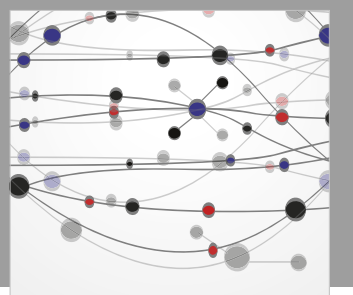

The Scientific World Journal Dentistry

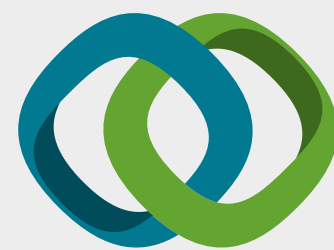

Hindawi

Submit your manuscripts at

www.hindawi.com
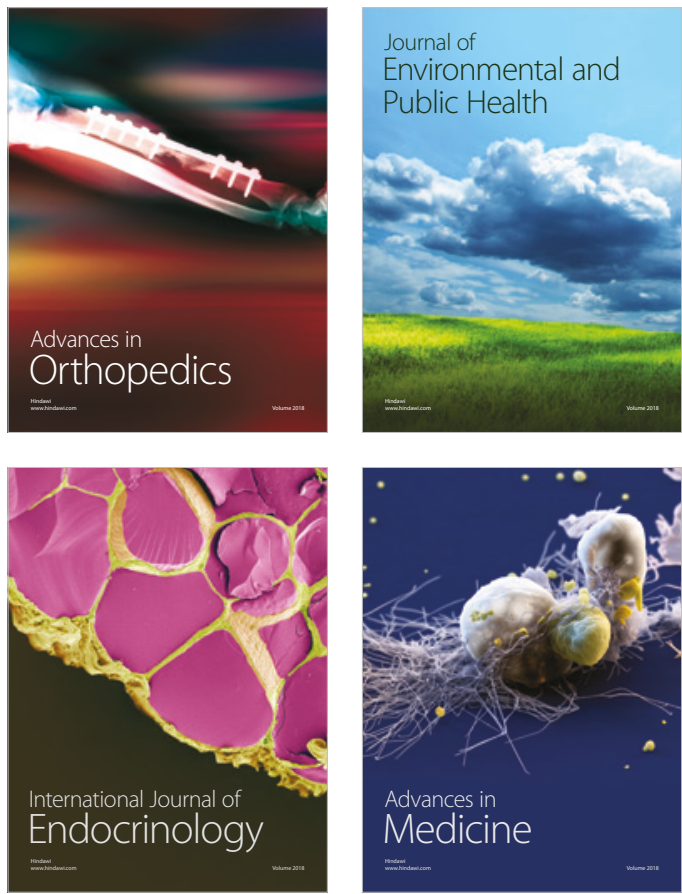
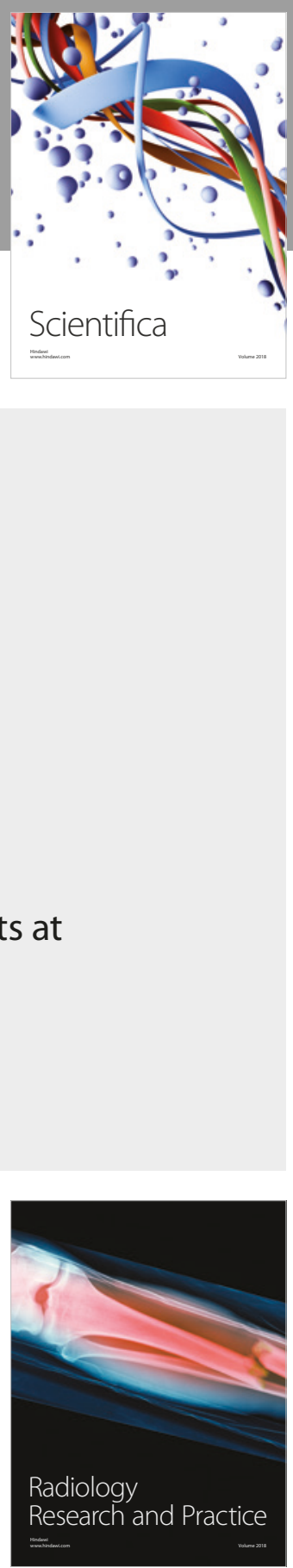

Scientifica

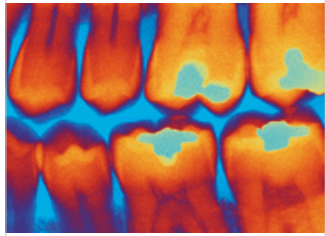

Case Reports in

Dentistry
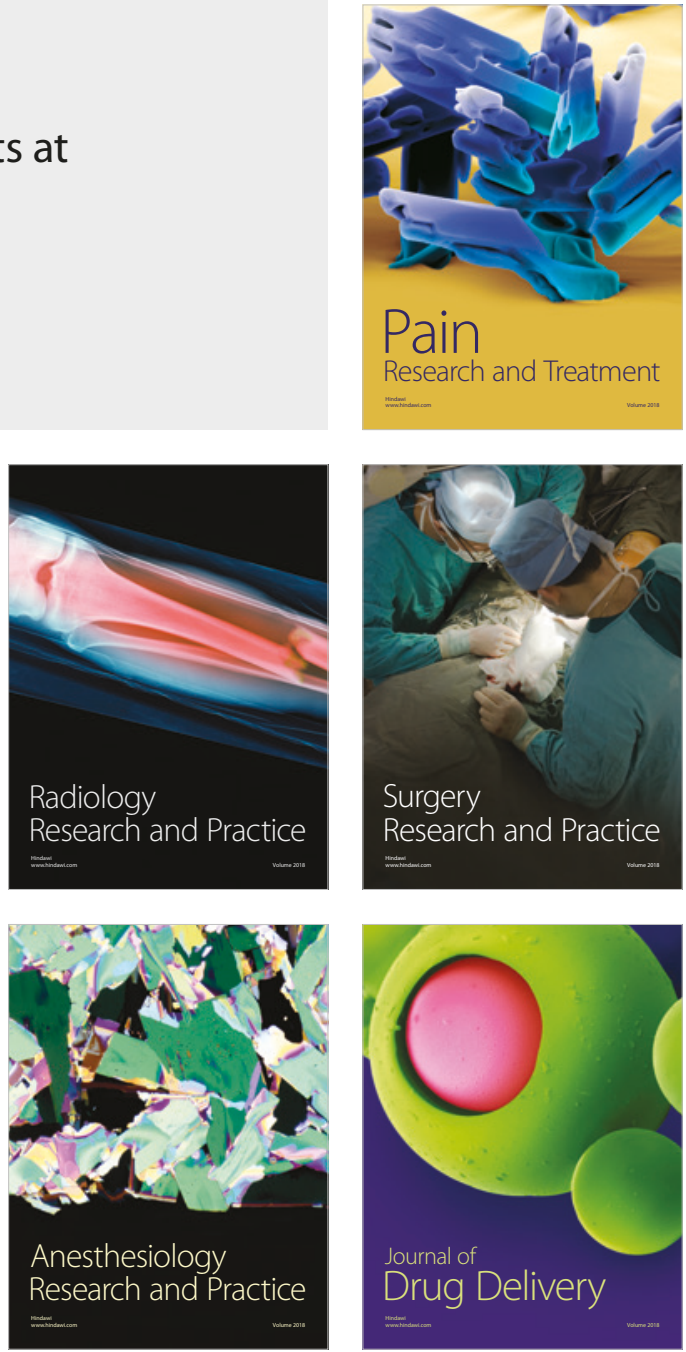